\title{
SMOKING PRACTICES IN JORDANIAN PEOPLE AND THEIR IMPACT ON SEMEN QUALITY AND HORMONAL LEVELS AMONG ADULT MEN
}

\author{
Hisham Y. Al-Matubsi', Reem A. Kanaan², Farqad Hamdan³, Maher Salim4, Ghaleb A. Oriquat ${ }^{4}$, Othman A. \\ Al-Hanbali \\ ${ }^{1}$ Faculty of Pharmacy, Applied Science University, Amman, Jordan \\ ${ }^{2}$ School of Pharmacy, Al-Zaytoonah Private University of Jordan, Amman, Jordan \\ ${ }^{3}$ College of Medicine, Al-Nahrain University, Baghdad, Iraq \\ ${ }^{4}$ Faculty of Pharmacy and Medical Sciences, Al-Ahliyya Amman University, Amman, Jordan \\ ${ }^{5}$ Faculty of Pharmacy, Philadelphia University, Amman, Jordan
}

\section{SUMMARY}

Despite worldwide anti-smoking campaigns, cigarette smoking prevalence is increasing in the third-world countries. It is now regarded as the most important public health issue. Here, we study the current smoking situation and investigate the impact of cigarette smoking on semen quality and hormonal levels among adult people. Furthermore, we suggest various strategies to reduce smoking consumption among young individuals. A cross-sectional data from 804 adult smoker subjects (male $n=530$ and female $n=274$ ) aged between 15 and 45 years were analyzed. One hundred and eleven males were agreed for further evaluation of their semen quality and hormones compared with 93 age-matched non-smoking males. This study showed that the major factors initiating smoking among women were friends' influence (49\%), life pressures (16\%) and parental imitation (14\%). The major reasons in men was friends' influence (65\%). Furthermore, $61 \%$ of women and $89 \%$ of men smoke in public implying social acceptance or even encouragement of this habit. This study also found that low-income Jordanians consume more tobacco materials than those in the middle-and higher income. Furthermore, smokers had significantly lower $(p<0.001)$ sperm concentration and motility values and higher $(p<0.001)$ serum testosterone and luteinizing hormone $(\mathrm{LH})$ levels than non-smokers.

Key words: smoking, semen, male hormones, tobacco, cigarette

Address for correspondence: H. Y. Al-Matubsi, Faculty of Pharmacy, Applied Science University, Amman, Jordan. E-mail: almatubsi@yahoo.com

\section{INTRODUCTION}

Despite worldwide anti-smoking campaigns, cigarette smoking is growing in third-world countries (1). Tobacco is the second leading cause of death globally, resulting in nearly five million deaths a year (2). Tobacco is the only legal product that causes the death of about half of its regular users (3). On the other hand, a decline in smoking rate was recently documented in many countries such as the United States of America, Finland, Australia and Canada (4).

The Middle East studies reported that at least 30 to $40 \%$ of Arab men were regular smokers despite a high tax applied by Arab governments which is almost three times the original price of the tobacco products. Smoking rates documented for Jordanians appear to be rising especially in 12 to 18 year age category. More than $50 \%$ of the Jordanian population is considered as regular smokers $(2,3)$.

Smoking has been called the chief, avoidable cause of death in Jordan (1). It is now regarded as the most important public health issue $(5,6)$. In addition, $30 \%$ of Jordanian men aged 18 or more are smokers compared with $26 \%$ of the USA men. In contrast, similar age, cultural issues and social pressure may result in low $15 \%$ prevalence rate of smoking among Jordanian women (7).
It is wide-spread knowledge among the Jordanian population that smoking is the main risk factor for lung and heart diseases $(2,8)$. Only a few smokers in Jordan will acknowledge that they should not smoke indoors (3). This indicates high social acceptance of smoking. Moreover, it indicates that "smokers" either do not think of themselves as engaging in hazardous behaviour or they do not care.

The highest prevalence of smoking has been observed in young adult males during their reproductive period ( $46 \%$ of first hand smokers between 20 and 39 years) (9). Cigarette smoke contains known mutagens and carcinogens. Therefore, there is a great concern that smoking may have unfavorable effects on male reproduction (10).

Various studies examining the effects of smoking on semen quality and male sex hormones have been carried out worldwide (11-13), but their results were inconsistent. Some studies have observed that cigarette smoking has detrimental effect on semen quality, especially among those who are heavy smokers or who have been smoking for many years (14). Other studies have shown a reduction in sperm concentration, motility and the percentage of normal morphology among infertile patients who smoke (12).

This study was conducted to determine the current smoking practice in Jordan. 
A questionnaire was used to study the factors leading to the habit of smoking and tobacco dependence among young Jordanian men and women. Finally, to explore the impact of cigarette smoking on semen quality and male hormonal levels.

\section{MATERIALS AND METHODS}

\section{Participants}

This was a cross-sectional study carried out in Amman, Jordan from October 2008 until October, 2009. Eight hundred and four smokers from various regions in and around Amman were randomly selected and agreed to participate in our study. In all of 530 men and 274 women from different social classes participated. Their age ranged from 15 to 45 years. For the purpose of the study a smoker was defined as a person who smokes one or more cigarettes a day. Additionally, 111 out of 150 healthy adults, who smoke 10 or more cigarettes a day, agreed with examination of their semen quality and hormones. This group was compared with 93 age-matched non-smoking males.

Information about their current smoking habits was obtained from subjects, either by self-report or direct interview using a written anonymous questionnaire. Information on their reproductive, medical, occupational and lifestyle factors was also obtained by means of this questionnaire. This study was performed using a protocol for the protection of human subjects approved by local ethical committees. Written informed consent was obtained from each subject. Physical examination of all subjects was performed. Subjects with hypertension $(n=5)$, cardiovascular disorders $(n=2)$, semen dysfunction causes $(n=1$; such as varicocele and chronic prostatitis), or with any history of previous or current genital diseases were excluded.

\section{Semen collection and analysis}

Semen samples were collected by masturbation in a sterile wide-mouthed specimen container after 2 to 4 days of abstinence. Time of ejaculation, abstinence period, and spillage (if any) was recorded. All the semen samples were processed and analyzed by the same experienced laboratory assistant at the private clinic in accordance with the guidelines published by the World Health Organization (WHO) guideline (15).

Four semen and sperm parameters were studied. Three were measured and one was derived. The measured parameters were semen volume, sperm concentration and percentage of normal sperm motility. Total sperm count was derived by multiplying semen volume by sperm concentration for each sample. Samples were liquefied at $37^{\circ} \mathrm{C}$ and evaluated immediately thereafter, according to WHO guidelines (16). The time to liquefaction was recorded and ejaculated volume was measured by a graduated cylinder or by aspirating the whole sample into a wide-mouthed pipette by means of a mechanical device (16). The sperm motility assessment was carried out and repeated on $10 \mu \mathrm{l}$ aliquot of semen according to the WHO criteria (16) and the average value for both samples was considered.
For the assessment of sperm concentration, a $50 \mu 1$ aliquot of the thoroughly mixed liquefied semen of each subject was diluted into a $950 \mu 1$ diluents and mixed for $10 \mathrm{~min}$. The diluents consisted of $50 \mathrm{~g}$ of sodium carbonate $\left(\mathrm{NaHCO}_{3}\right), 10 \mathrm{ml} 40 \%$ formaldehyde and distilled water up to 1 litre. One drop of the diluted specimen was transferred to a Neubauer haemocytometer chamber (17), which was allowed to stand for $5 \mathrm{~min}$ in a humid environment before the cells were counted under a microscope (x400). Only sperm with tails were counted.

\section{Hormone analysis}

Blood were collected from participants and centrifuged when the semen samples were collected. The samples were stored at $4^{\circ} \mathrm{C}$ until analysis. Sexual hormone analysis included luteinizing hormone $(\mathrm{LH})$, follicle stimulating hormone (FSH) [immunoradiometric assay (IRMA); ICN, High Wycombe, Bucks, UK], testosterone and sex hormone binding globulin (SHBG) (radioimmunoassay; Immunotec, Marseille, France) levels were measured in all smokers $(\mathrm{n}=111)$ and control non-smokers $(\mathrm{n}=93)$.

\section{Statistical analysis}

Participants were grouped into smokers, and non-smokers. Significance tests were two-tailed and $\mathrm{p}$ values $<0.05$ are regarded as statistically significant. Statistical analysis was performed by a bio-statistician using SPSS statistical software (SPSS Inc., Chicago, IL, USA).

\section{RESULTS}

\section{Factors initiating smoking}

Figure 1A showes the factors which initiated smoking in women. It is apparent that friends have the greatest influence (49\%). This was followed by life pressures $(16 \%)$, imitation of parents (14\%), and curiosity ( $8 \%$ ). A husbands' wish, television, and strong personality feelings were the least $(5 \%, 3 \%$ and $2 \%$, respectively). Similarly, in men, friends influence was the most important factor $(65 \%)$. All the other factors had almost a similar effect. Life pressures and curiosity (9\%), parents' imitation (8\%), and manhood feeling (7\%) (Fig. 1B).

\section{Effect of parents and family members on smoking prevalence}

In this step, the study of the question of parents' smoking habits is of particular importance in attracting their children to do the same. The results showed that only $84 \%$ of women and $74 \%$ of men did have either a parent or relative who smoked (Fig. 2A and B, respectively) which means that the majority of both sexes will smoke if their parents do. Further, to investigate whether the correspondents are truly satisfied with their smoking habit, we asked the following question (What are you going to do when you see your young son, brother or sister smoking?). In response, $77 \%$ of women and $80 \%$ of men declared their objection. Many said that they would blame themselves. 


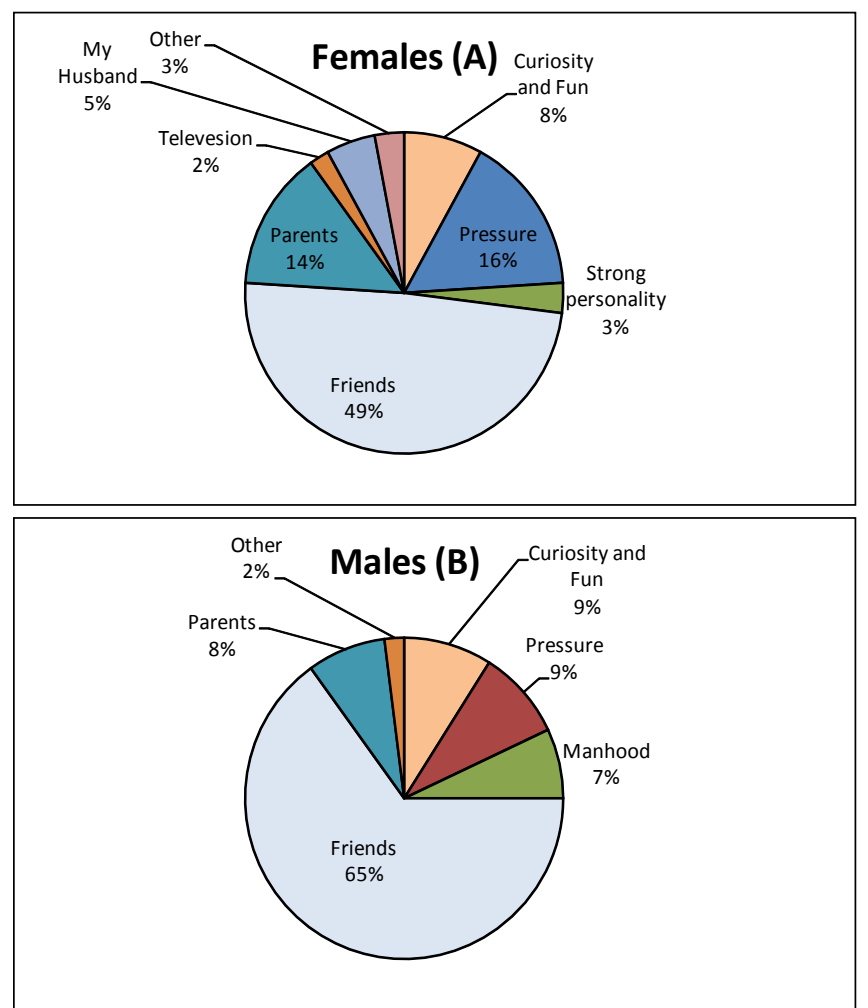

Fig. 1: Distribution of smokers according to the initiating factors for smoking. $A$ in Females, $B$ in Males.

\section{Effect of society acceptance on smoking habit}

The percentage of participants claiming to smoke in public is fairly high. Only $39 \%$ of women smoke in private compared to $11 \%$ of men.
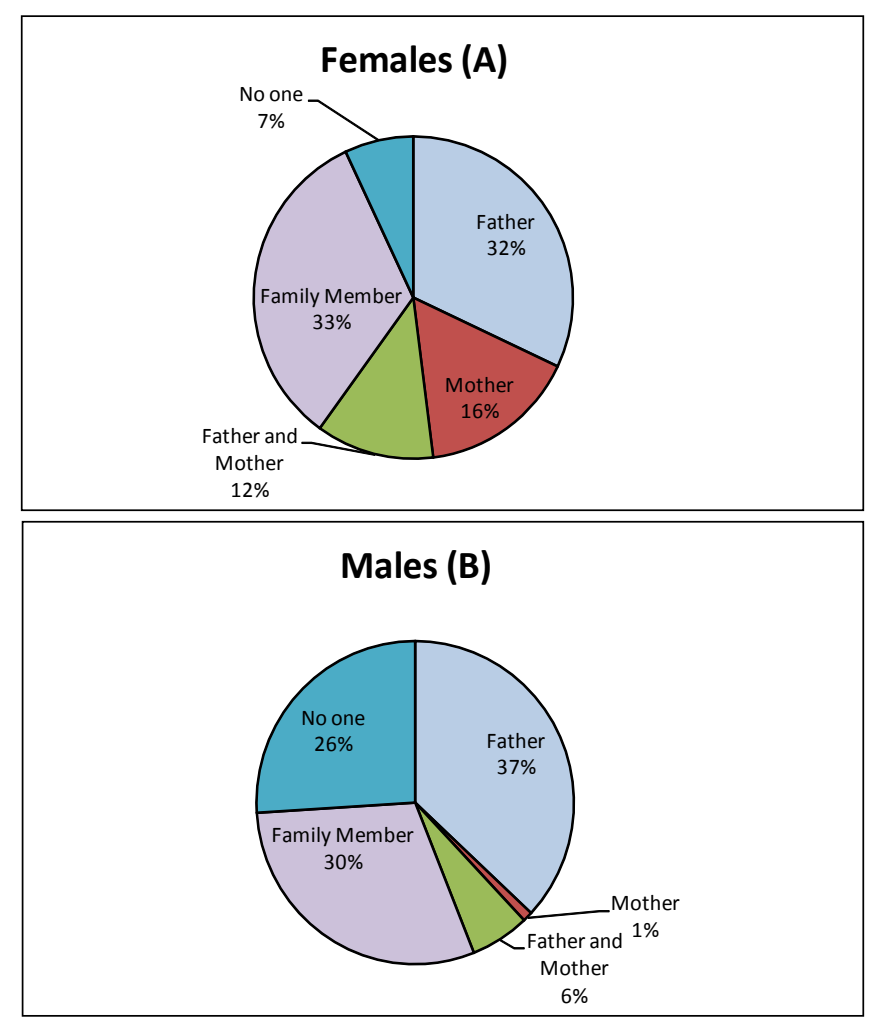

Fig. 2: Distribution of smokers according to the effect of their parent and/or relatives on smoking habit. A in Females, $B$ in Males.

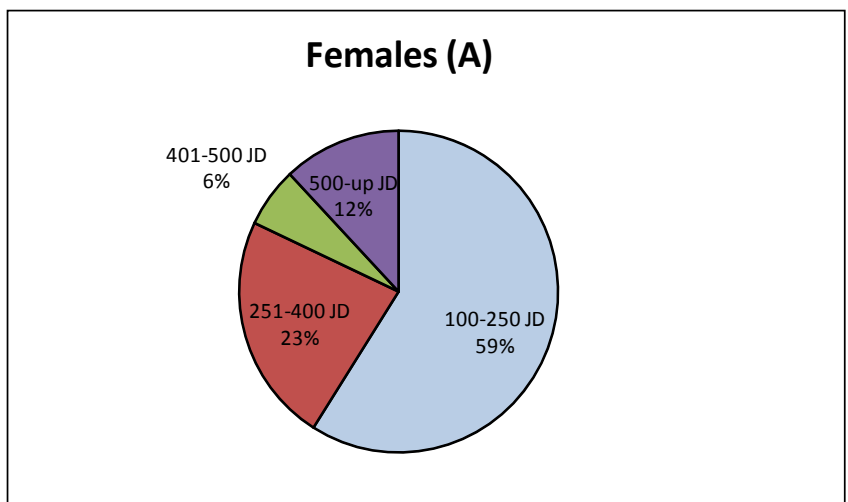

Males (B)

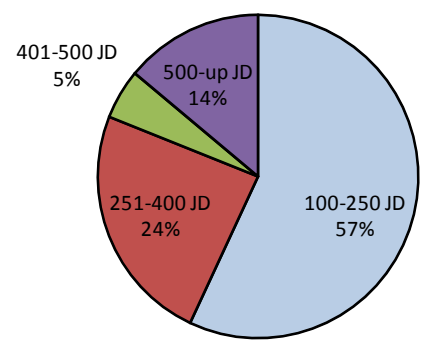

Fig. 3: Distribution of smokers according to their income. A in Females, $B$ in Males.

\section{Effect of monthly income on smoking prevalence}

The lower the income, the higher the smoking prevalence, $59 \%$ of women and $52 \%$ of men fall into the category of very low income (100-250 JD/month), $23 \%$ of women and $24 \%$ of men fall into the low category income (251-400 JD/month), $6 \%$ of women and $5 \%$ of men fall into the high $(401-500 \mathrm{JD} /$ month) category income, whereas, $12 \%$ women and $14 \%$ men belong to the very high category income $(>500 \mathrm{JD} / \mathrm{month})$ (Fig. 3A and B).

\section{The best ways to quit smoking}

For women, the options of strong will to maintain good health (4\%), applying more taxes to increase tobacco prices (11\%), spreading the idea that smokers smell bad (12\%), presenting more education about the risks of smoking (29\%), banning cigarettes from the market (37\%), and other ways (7\%) were the solutions for stopping smoking. The results for men were $9 \%, 9 \%, 8 \%, 24 \%, 44 \%$, and $0 \%$ respectively. To further emphasize this point, we asked the following question: (Is smoking socially unacceptable?). $40 \%$ of both men and women answered, "yes".

\section{Semen Analysis}

The results of the semen analyses and reproductive hormones are given in Table 1. Smokers had significantly lower sperm concentration and motility values $(\mathrm{p}<0.001)$ than nonsmokers $(50.84 \pm 15.54$ versus $58.48 \pm 18.13$ and $50.036 \%$ versus $54.38 \%$; respectively). Smoking, however, had a statistically non-significant effect on ejaculatory volume $(\mathrm{p}>0.05)$. 
Table 1. Shows the basic characteristics of semen and male sex hormones of participants

\begin{tabular}{|l|c|c|}
\hline Semen parameters & $\begin{array}{c}\text { Smokers } \\
(\mathbf{n}=111)\end{array}$ & $\begin{array}{c}\text { Non-smokers } \\
(\mathbf{n}=93)\end{array}$ \\
\hline Volume $(\mathrm{ml})$ & $2.9 \pm 0.62$ & $3.1 \pm 0.67$ \\
\hline Sperm concentration $\left(\times 10^{6} / \mathrm{ml}\right)$ & $48.84 \pm 15.54^{*}$ & $58.48 \pm 18.13$ \\
\hline Sperm motility \% & $45.04 \pm 7.99^{*}$ & $54.38 \pm 7.14$ \\
\hline Total sperm count $(\times 106)^{b}$ & 141.64 & 181.98 \\
\hline Sex Hormone concentrations & & \\
\hline Testosterone (nmol/l) & $18.07 \pm 2^{* *}$ & $16.19 \pm 2.70$ \\
\hline SHBG (nmol/l) & $29.5 \pm 0.3$ & $30.2 \pm 0.6$ \\
\hline Luteinizing hormone "LH" (IU/l) & $4.23 \pm 0.61^{* *}$ & $3.4 \pm 0.64$ \\
\hline $\begin{array}{l}\text { Follicle stimulation hormone "FSH" } \\
\text { (IU/l) }\end{array}$ & $3.66 \pm 0.64$ & $3.52 \pm 0.65$ \\
\hline
\end{tabular}

a Percentage of normal sperm motility

${ }^{b}$ Total sperm count derived by multiplying volume times sperm concentration

*Statistically significantly lower compared with the non-smoker group $(p<0.001)$

${ }^{*}$ Statistically significantly higher compared with the non-smoker group $(p<0.001)$

\section{Serum Hormones}

Serum testosterone and LH levels were significantly $(\mathrm{p}<0.001)$ higher in smokers than those in non-smokers $(18.07 \pm 2$ versus $16.19 \pm 2.70 \mathrm{nmol} / 1$ and $4.23 \pm 0.61$ versus $3.4 \pm 0.64 \mathrm{IU} / \mathrm{l}$; respectively). No significant differences were found between nonsmokers and smokers in SHBG and FSH levels. Testosterone, LH, SHBG and FSH levels were not significantly correlated with any of semen parameters (data not shown).

\section{DISCUSSION}

Although many previous studies have examined the incidence of smoking among adolescents, there have been very few nationwide studies determining the causes of smoking habits and suggesting ways to combat them $(2,6,8)$.

Unlike other studies, this study evaluated the current smoking situation in and around Amman, its initiation factors, social acceptance and the association between income and smoking of this widespread habit in Jordanian people.

Warren et al. (1) reported that $35 \%$ of the adult populations in Jordan are current smokers and the percentage was raised to $52 \%$ in males and $18 \%$ in females.

In agreement with previous studies $(2,8)$, this study showed that the average smoking rate is high among some population groups, particularly the youth, women, and low income earners.

Data obtained from this study, indicate that the increase in smoking habit is due to following three factors; friends' influence, an acquired lifestyle from smoking parents (either one or both), mainly older siblings and social acceptance.

The early onset of smoking is related to the notion that smoking is a sign of maturity and manhood (1). Many children are attracted by advertising and other messages promising a fashionable, young and independent lifestyle with cigarettes as imperative symbols (18). This correlates with primary outcome of this study that social acceptance is the number one motivational factor for Jordanian adolescents to become tobacco smokers.
The result of our study showed that the high risk of smoking initiation was also related to parents being heavy smokers themselves. This is in agreement with previous observations suggesting that parental reactions, attitudes, and opinions about smoking have a great influence on whether or not children smoke (6).

Based on the data obtain from this study, adolescents who claimed to be proud of practicing smoking and showed no interest in quitting the habit shared an increased rejection to their loved ones becoming addicted. This clearly reveals the double standards in evaluating the tobacco smoking habit.

Approximately $80 \%$ were not willing to quit smoking or even to modify their smoking habits. The majority of the participants acknowledged that they do not feel ashamed of smoking in public. This indicates a high social acceptance of smoking mainly for women as our study revealed that only $39 \%$ of women smoke secretly. This study indicates that to be surrounded by smoking friends and feeling"out" if you are not a smoker yourself, was a strong motivational factor for most people to become regular smokers which is in agreement with Al-Wahadani and Linden (8). Their results indicate that pupils having at least two smoker friends were five times more likely to switch from being "trial" smokers to regular ones.

This study also demonstrated a strong positive correlation between monthly income and smoking prevalence (the lower the income, the higher is the chances that the person will become a smoker). This may be attributed to the substantially low level of education combined with a high level of stress.

Tobacco dependence is a chronic condition that often requires repeated intervention. Quitting tobacco use is difficult and may require multiple attempts, as users often relapse because of withdrawal symptoms (19). Research projects suggest that nicotine is the psychoactive drug in tobacco products that produces dependence and addiction just as heroin, cocaine, or alcohol (18). Lack of Nicotine in blood produces irritable, anxiety, difficulty in concentration, and increased appetite (20).

Eighty percent of the participants in the study thought that the only way to quit smoking is by banning tobacco cigarettes from the market. This clearly shows that unassisted attempts at quitting might not be successful except for those who have very strong will power.

Smoking is a lifestyle hazard for both active and passive smokers. Although much is known now about the carcinogens in tobacco cigarette smoke and their resultant effect on organs like lungs and urinary bladder, their effects on fertility status have been less documented. The effect of smoking on semen quality has been investigated in a number of cross-sectional studies. Results have been conflicting. Some investigators have reported, as with the present study's findings, that those smokers have a lower semen quality in terms of the conventional semen characteristics like sperm concentration, total count and motility $(13,14,21)$. Others have reported no effect of smoking on semen quality (22, 23). Recently, it has been reported that smoking significantly contributes to the development of morphological abnormalities (24) and reduced sperm counts besides motility defects $(24,25)$ which further supports our finding.

In addition, in a meta-analysis covering 27 studies on sperm quality among smokers, an average reduction of $13 \%$ in sperm concentration, $10 \%$ in motility and $3 \%$ in normal morphology was observed (11). In this study, no significant differences in semen 
volume between non-smokers and smokers we found. Contrary to our findings, Pasqualotto et al. (21) reported a decline in semen volume with increases in the number of cigarettes smoked. The major shortcoming of this study is the lack of accurate smoking dose information.

Furthermore, the present study does not include information about body mass index (BMI), and obesity which could potentially affect the study findings. However, previous studies on the association of smoking and these variables showed inconsistent results. Recently, the results of Caks and Kos (26) does not support the hypothesis that smoking affects an abdominal fat distribution profile predominantly in the form of central adiposity as reported earlier by Shimokata et al. (27).

In accordance with other studies, our group of smokers showed higher testosterone and LH levels. However, there is no clear trend associated between smoking and SHBG or FSH $(13,25)$.

On the other hand, recently Saadat (28) and Pasqualotto et al. (21) showed no increase in the testosterone, FSH or LH levels.

The significantly elevated LH in smokers suggests a central activation of Leydig cells, which explains elevated serum testosterone levels. Whether smoking increases LH and testosterone by itself or whether men with elevated hormone levels are more prone to becoming addicted to cigarette smoking remains unclear.

The lack of correlation between any of the semen parameters and serum testosterone, $\mathrm{LH}$ and FSH suggests that any changes in gonadotrophin secretion or spermatogenesis in this study are not due to a loss of testicular steroidogenic potential.

The mechanism behind the harmful effect of smoking on semen quality is not fully understood. Disturbance of the hypothalamo-pituitary-gonadal system (27) or mild hypoxia caused by the disruption of the testicular microcirculation (28) are possible explanations, but a direct toxic effect of the many chemical components in the cigarette smoke on the germinative epithelium is a more likely explanation (29). Furthermore, oxidants in cigarette smoke are thought to damage sperm DNA, and smokers have more oxidative DNA damage in their sperm than do non-smokers (30).

Finally we recommend that this is time to stop scolding children and young people for what goes wrong and start assisting them to make positive choices. The first practical and effective step should be to encourage people to give up smoking (self motivation) by increasing knowledge about the side effects of smoking and to prevent future generations from smoking. Smoking parents should share their struggles to quit with their children indicating cigarettes' harmful effects and keeping a smoke-free home.

Smoking should be strictly banned in public areas and on public transportation. Additional double or triple tax should be applied on every tobacco related material. The benefit of extra money should be used to educate people about smoking hazards. Government should impose an age restriction on cigarette purchases. Smokers can gradually quit with the help of medicines such as Nicotine gum, patches, lozenges or any other dosage form. The use of smokeless tobacco such as Aeros is also recommended.

Bearing in mind that the most regular and the heaviest smokers are presently found among the women and men in childbearing years, it is most important that information about the harmful effects of tobacco on reproduction is available and widely disseminated among the general public and, in order to achieve this, the following steps should be taken forth with:
Local Education Authorities should include in their health education curricula specific information about the dangers of cigarette smoking by both partners before and particularly during pregnancy; leaflets containing the above information should also be widely distributed and available in all doctors' surgeries, hospital waiting rooms, libraries, family planning clinics, etc.; the Government should instruct the tobacco industry to alter the current warning "Tobacco seriously damages health" to "Tobacco damages health and causes serious harm to the unborn child. Do not smoke while pregnant"; to establish smoke free zone restaurants, buses, etc. and introduce heavy fines. Whether these recommendation are really applicable to the Jordanian society or not is a big issue. Yet we need to raise the community's awareness of smoking health risks from various perspectives, legally, economically and socially, with special emphasis on the benefits of quitting smoking.

Further studies are needed to investigate the long-term effects and benefits of smoking withdrawal on conventional semen parameters.

\section{REFERENCES}

1. Warren CW, Jones NR, Peruga A, Chauvin J, Baptiste JP, Costa de Silva V; Centers for Disease Control and Prevention (CDC). Global youth tobacco surveillance, 2000-2007. MMWR Surveill Summ. 2008 Jan 25;57(1):1-28.

2. Haddad LG, Malak MZ. Smoking habits and attitudes towards smoking among university students in Jordan. Int J Nurs Stud. 2002 Nov;39(8):793802.

3. Ma'ayed SP. Jordan: mass media campaign combating smoking requires serious commitment and not just words [Internet]. Geneva: WHO; 2004 [updated 2011; cited 2010 Dec 2]. Available from: http://www.who.int/ tobacco/training/success_stories/en/best_practices_jordan_media.pdf.

4. White M, Bush J, Kai J, Bhopal R, Rankin J. Quitting smoking and experience of smoking cessation interventions among UK Bangladeshi and Pakistani adults: the views of community members and health professionals. J Epidemiol Community Health. 2006 May;60(5):405-11.

5. Ismail SR, Kholeif SF, Mokhtar MM. Chromosome damage in passive smoker females. J Egypt Public Health Assoc. 1998;73(1-2):111-23.

6. Kandela P. Jordan starts campaign to tackle high rates of smoking. Lancet. 2000 May 20;355(9217):1800.

7. Burgan SZ. Smoking behavior and views of Jordanian dentists: A pilot survey. Oral Surg Oral Med Oral Pathol Oral Radiol Endod. 2003 Feb;95(2):163-8.

8. Al-Wahadni A, Linden GJ. The effects of cigarette smoking on the periodontal condition of young Jordanian adults. J Clin Periodontol. 2003 Feb;30(2):132-7.

9. Langgassner J. Rauchgewohnheiten der österreichischen Bevölkerung. Statistische Nachrichten. 1999;5:319-26.

10. Grant ECG. Allergies, smoking and the contraceptive pill. In: Hemmings GP, editor. Biological aspects of schizophrenia and addiction. New York: Wiley; 1982.

11. Vine MF. Smoking and male reproduction: a review. Int J Androl. 1996 Dec;19(6):323-37.

12. Zinaman MJ, Brown CC, Selevan SG, Clegg ED. Semen quality and human fertility: a prospective study with healthy couples. J Androl. 2000 Jan-Feb;21(1):145-53.

13. Ramlau-Hansen CH, Thulstrup AM, Aggerholm AS, Jensen MS, Toft $\mathrm{G}$, Bonde JP. Is smoking a risk factor for decreased semen quality? A cross-sectional analysis. Hum Reprod. 2007 Jan;22(1):188-96.

14. Künzle R, Mueller MD, Hänggi W, Birkhäuser MH, Drescher H, Bersinger NA. Semen quality of male smokers and nonsmokers in infertile couples. Fertil Steril. 2003 Feb;79(2):287-91.

15. World Health Organization. WHO laboratory manual for the examination of human semen and sperm-cervical mucus interaction. 4 th ed. Geneva: WHO; 1999.

16. World Health Organization. WHO laboratory manual for the examination of human semen and semen-cervical mucus interaction. 3rd ed. Geneva: WHO; 1992. 
17. Auger J, Eustache F, Ducot B, Blandin T, Daudin M, Diaz I, et al. Intraand inter-individual variability in human sperm concentration, motility and vitality assessment during a workshop involving ten laboratories. Hum Reprod. 2000 Nov;15(11):2360-8.

18. Horn WR, Rutishauser Ch. Considering and tackling tobacco smoking in the context of adolescent development. Ther Umsch. 2007 Feb;64(2):91-7. (In German.)

19. Mester R, Toren P, Ben-Moshe Y, Weizman A. Survey of smoking habits and attitudes of patients and staff in psychiatric hospitals. Psychopathology. 1993;26(2):69-75.

20. Raupach T, Nowak D, Hering T, Batra A, Andreas S. Smoking and pulmonary diseases, positive effects of smoking cessation. Pneumologie. 2007 Jan;61(1):11-4. (In German.)

21. Pasqualotto FF, Sobreiro BP, Hallak J, Pasqualotto EB, Lucon AM. Cigarette smoking is related to a decrease in semen volume in a population of fertile men. BJU Int. 2006 Feb;97(2):324-6.

22. Trummer H, Habermann H, Haas J, Pummer K. The impact of cigarette smoking on human semen parameters and hormones. Hum Reprod. 2002 Jun;17(6):1554-9.

23. Jensen TK, Jørgensen N, Punab M, Haugen TB, Suominen J, Zilaitiene B, et al. Association of in utero exposure to maternal smoking with reduced semen quality and testis size in adulthood: a cross-sectional study of 1,770 young men from the general population in five European countries. Am J Epidemiol. 2004 Jan 1;159(1):49-58.

24. Gaur DS, Talekar MS, Pathak VP. Alcohol intake and cigarette smoking: impact of two major lifestyle factors on male fertility. Indian J Pathol Microbiol. 2010 Jan-Mar;53(1):35-40.
25. Richthoff J, Elzanaty S, Rylander L, Hagmar L, Giwercman A. Association between tobacco exposure and reproductive parameters in adolescent males. Int J Androl. 2008 Feb;31(1):31-9.

26. Caks T, Kos M. Body shape, body size and cigarette smoking relationships. Int J Public Health. 2009;54(1):35-9.

27. Shimokata H, Muller DC, Andres R. Studies in the distribution of body fat. III. Effects of cigarette smoking. JAMA. 1989 Feb 24;261(8):1169-73.

28. Saadat M. Serum levels of testosterone and gonadotrophins with respect to smoking status and genetic polymorphism of GSTT1. Mol Biol Rep. 2009 Jul;36(6):1353-6.

29. Vermeulen A. Environment, human reproduction, menopause, and andropause. Environ Health Perspect. 1993 Jul;101 Suppl 2:91-100.

30. Collin O, Kilter S, Bergh A. Tobacco smoke disrupts testicular microcirculation in the rat. Int J Androl. 1995 Jun;18(3):141-5. Erratum in: Int J Androl 1995 Aug;18(4):230.

31. Zenzes MT. Smoking and reproduction: gene damage to human gametes and embryos. Hum Reprod Update. 2000 Mar-Apr;6(2):122-31.

32. Horak S, Polanska J, Widlak P. Bulky DNA adducts in human sperm: relationship with fertility, semen quality, smoking, and environmental factors. Mutat Res. 2003 May 9;537(1):53-65.

Received June 22, 2010 Accepted in revised form February 17, 2011 